\title{
Aproximación a ciertas nociones de historicidad en la prensa colombiana durante la Independencia e inicios de la República en Colombia (1810-1827)
}

\section{Approximation to certain notions of historicity in the Colombian press during the Independence and beginnings of the Republic in Colombia (1810-1827)}

\author{
Rodrigo de J. García Estrada ${ }^{1}$ \\ Universidad de Antioquia (Colombia)
}

Recibido: 23-02-16

Aprobado: 19-04-17

\section{Resumen}

Mediante un estudio sistemático de la prensa publicada en distintas ciudades de la actual Colombia durante la Independencia y los primeros años de la república de Colombia (llamada por los historiadores Gran Colombia, para no confundirla con la actual) se analiza el contenido de los conceptos utilizados por los colaboradores y editores de los periódicos tratando de entender la semántica de nociones relacionadas con la historicidad, entre otros: historia, devenir, tiempo, permanencia y cambio; pasado, presente y futuro. Se muestran las evidencias de temporalidad propias del proceso revolucionario a partir de 1810, analizando la aceleración de los acontecimientos y su frecuencia, que dificultaba a los ciudadanos su registro y discernimiento.

Palabras-clave: historia, historicidad, tiempo, revolución, aceleración, permanencia, cambio, agente, futuro.

\footnotetext{
${ }^{1}$ (rodrigo.garcia@udea.edu.co). Doctor en Historia y profesor titular de la Universidad de Antioquia. Una parte de esta reflexión se hizo en el marco de un proyecto financiado por el Comité de Investigaciones de la Universidad Andina Simón Bolívar (Quito, Ecuador) en 2015 y uno de sus avances fue presentado en el IX Congreso Ecuatoriano de Historia, Universidad Andina Simón Bolívar, (Ecuador), julio 15 a 18 de 2015.
} 


\begin{abstract}
Through a systematic study of the press published in different cities of present-day Colombia during the Independence and the first years of the Republic of Colombia (called by historians Gran Colombia, not to confuse it with the current one), the content of the concepts used by newspaper contributors and editors trying to understand the semantics of notions related to historicity, among others: history, future, time, permanence and change, past, present and future. It shows the evidence of temporality that allow to locate a revolutionary process from 1810, which implied the speed of events and its succession, which made it difficult to register and discern. Reason why, appeared the first newspapers, interested in not letting out any important event. It was possible to verify the coexistence and overlap of two regimes of historicity, the first Ciceronian who sought to teach and moralize, history magistra vitae, and the second, modern court, with emphasis on a changing history, made in part by men, and determined by concepts and passions that, by becoming opinions accepted by the greater part of the community, provoke the appearance of the individuals necessary to lead to the new, the unpublished and the best.
\end{abstract}

Key-words: History, Historicity, Time, Revolution, Acceleration, Permanence, Change, Agent, Future.

\title{
Introducción
}

Esta pesquisa, en sus inicios, tuvo por objeto las diferentes acepciones del término "historia" y los usos políticos que se le dio al saber histórico durante el proceso independentista en la Nueva Granada durante la Primera República. La motivación de esta exploración conceptual derivó de la inquietud por la situación en que se vieron inmersos los actores históricos que participaron de la revolución política y cultural derivada de la crisis de la monarquía española entre 1808 y 1815. Así fue posible conocer las connotaciones del vocablo "historia" al momento de ser empleado en los discursos políticos de dicho período y dilucidar algunos usos del saber histórico en momentos en los que su difusión fue posible mediante la lectura pública de la prensa y del estudio de la historia en las tertulias, cafés y sociedades literarias existentes en los centros urbanos $^{2}$.

\footnotetext{
2 El historiador Renán Silva, muestra cómo las tertulias y sociedades literarias sirvieron a la difusión de la prensa, "transformando su lectura en un acto colectivo" y fueron su soporte. Renán Silva, Prensa y revolución a finales del siglo XVIII, Medellín, La Carreta, 2004, p. 39. Ver además: Jaime E. Rodríguez O., La independencia de la América española, México, Fondo de Cultura Económica, Colegio de México, Fideicomiso Historia de las Américas, 2005, p. 88.
} 
El presente artículo, elaborado a partir de un rastreo sistemático de columnas publicadas por la prensa neogranadina entre 1810 y 1827 , analiza discursos, párrafos y alusiones precisas al término "historia", por cuanto se ha constatado que los formadores de opinión y ciudadanos que publicaron sus puntos de vista en estos impresos aluden a este vocablo, bien sea para pensar el estado de cosas que estaba experimentando la nación colombiana, con base en las lecciones de otros pueblos y civilizaciones del pasado lejano o próximo; bien para establecer por comparación el estado de avance en el proceso histórico de la humanidad, tomando como referente los países europeos; o bien fuera para establecer las diferencias y particularidades de la nación colombiana. En todos los casos, es evidente que no sólo se tiene un concepto de "historia", sino que se acude al conocimiento histórico para pensarse a sí mismos, y se puede inferir en sus palabras nociones sobre el tiempo y reflexiones en torno al papel de quienes enuncian dichos discursos para incidir desde sus acciones en el presente sobre el futuro colectivo.

\section{Contexto historiográfico}

En Colombia se han publicado numerosos estudios historiográficos sobre la historia de la Independencia y la República. Entre los pioneros de estos esfuerzos por establecer el conocimiento en torno al tema de la Independencia está Javier Ocampo López, quien logra ubicar los principales vacíos temáticos, propone a las futuras generaciones una agenda de trabajo y recopila la bibliografía producida hasta fines de la década de $1960^{3}$. Germán Colmenares, por su parte, en Convenciones contra la cultura aplicó las propuestas analíticas de Roland Barthes y Hayden White para su revisión de la historiografía decimonónica, centrándose en "las convenciones con las cuales se construye la representación histórica" " Caracteriza las tramas de los relatos históricos del siglo XIX, marcadas por el modelo de la tragedia y por los códigos y valores culturales y sociales defendidos por los historiadores. Ejemplifica su argumento a partir de un análisis de las convenciones usadas por José Manuel Restrepo en su obra La Historia de la Revolución de la República de Colombia, cuya estructura está basada en la tensión entre el afianzamiento de las leyes y las instituciones, de un lado, y las pasiones individuales y colectivas, del otro. Tensión que atraviesa el tema central de la obra de Restrepo: la formación del Estado y la nación colombianos ${ }^{5}$.

\footnotetext{
3 Javier Ocampo López, Historiografia y bibliografía de la emancipación del Nuevo Reino de Granada, Tunja, Universidad Pedagógica y Tecnológica de Colombia, 1969.

${ }^{4}$ Germán Colmenares, Las convenciones contra la cultura, Bogotá, Tercer Mundo, 1989, p. 40.

5 Ibid., pp. 176-182.
} 
Un estudio a profundidad en torno a la obra de José Manuel Restrepo es el de Sergio Mejía, quien señala que aquél se propuso darle referentes de identidad a los ciudadanos de la nueva república para influir en el presente y el futuro del país ${ }^{6}$. En su caracterización del pensamiento histórico de Restrepo, lo describe como alguien que tuvo como meta escribir una historia razonada de la liberación de América y de sus diferentes repúblicas como entidades autónomas e independientes de España ${ }^{7}$.

Por su parte, Daniel Gutiérrez Ardila estudia los primeros textos históricos publicados en Europa, como parte de la campaña de propaganda del estado colombiano para lograr el reconocimiento internacional como parte de la comunidad de naciones ${ }^{8}$. Su objeto no es el análisis de los conceptos de "historia" implicados en dichas obras, sino el interés político y diplomático de sus autores, los rasgos intelectuales de éstos y el contexto europeo en el que se dio su publicación. En torno a la obra de José Manuel Restrepo dice que se trató de una reflexión escrita para la posteridad, caracterizada por la rigurosidad de su investigación documental, la sutileza de sus argumentos y el estudio a profundidad del caso colombiano. Pero se destaca que su propósito en el ámbito internacional es "la promoción del reconocimiento del nuevo Estado y de la emigración europea" .

El libro de Alexander Betancourt Mendieta, Historia y nación. Tentativas de la escritura de la historia en Colombia, es la más ambiciosa empresa de reflexión historiográfica ya que intenta abarcar el conocimiento histórico desde José Manuel Restrepo hasta fines del siglo $\mathrm{XX}^{10}$. En lo atinente a los fines de este artículo, debe retomarse su planteamiento según el cual los hombres de letras del siglo XIX que escribieron Historia lo hicieron para defender sus posturas políticas y como copartícipes de la creación de la institucionalidad estatal. Y, en tal sentido, la obra de Restrepo fue el primer esfuerzo sistemático por entender los sucesos de la Independencia como el origen mismo de la República y punto axial desde el cual se interpretan los demás periodos del pasado nacional $^{11}$.

En 2007, Armando Martínez Garnica realizó un intento por establecer el "estado de la representación histórica" en torno a la Independencia de Colombia, señalando las principales temáticas abordadas por los historiadores profesionales y sus consensos interpretativos, entre las últimas décadas del siglo

\footnotetext{
${ }^{6}$ Sergio Mejía, La revolución en letras. La Historia de la Revolución de la República de Colombia de José Manuel Restrepo (1781-1863), Bogotá, Uniandes-Ceso, Universidad Eafit, 2007, p. 15.

7 Ibid., p. 219.

8 Daniel Gutiérrez Ardila, El reconocimiento de Colombia: Diplomacia y propaganda en la coyuntura de las restauraciones (1819-1831), Bogotá, Universidad Externado de Colombia, 2012.

9 Ibid., p. 153.

${ }_{10}$ Alexander Betancourt Mendieta, Historia y nación. Tentativas de la escritura de la historia en Colombia, Medellín, La Carreta, 2007.

${ }^{11}$ Ibid., pp. 27-29.
}

Araucaria. Revista Iberoamericana de Filosofia, Política y Humanidades, año 19, n 38. Segundo semestre de 2017. Pp. 393-417. ISSN 1575-6823 e-ISSN 2340-2199 doi: 10.12795/araucaria.2017.i38.18 
XX y comienzos del actual ${ }^{12}$. Con una mirada distinta, Catalina Reyes Cárdenas publicó su "Balance y perspectivas de la historiografía sobre Independencia en Colombia", en el que aborda los autores y textos decimonónicos, entre otros a Restrepo y su premisa teleológica, según la cual la Independencia era necesaria e "inspirada en el nacionalismo de los criollos que luchaban por una nueva nación moderna" "13. Valga decir que Reyes también analiza a José María Samper y José Manuel Groot, quienes dieron forma en el siglo XIX a las versiones liberal y conservadora de la independencia colombiana.

Quizás el historiador colombiano más dedicado a estudiar la historiografía decimonónica es Jorge Orlando Melo, en especial en su texto "La literatura histórica en la República", donde sostiene que la historia como género literario y científico surge después de la Independencia. Como ejemplo cita los textos de Jorge Tadeo Lozano y Francisco José de Caldas, que se vieron compelidos a registrar los hechos del 20 de julio de 1810 por su utilidad para el presente y la posteridad. La misma preocupación, según Melo, años después dio lugar a la obra de Restrepo, a quien considera "un buen representante de los ilustrados de fines del periodo colonial" ${ }^{\prime 14}$.

Con base en su trayectoria como historiógrafo, Melo abordó la semántica del concepto "historia" en Colombia, en un subcapítulo del Diccionario político y social del mundo iberoamericano. La era de las revoluciones, 1750-1850, publicado bajo la dirección de Javier Fernández Sebastián. En este artículo, el historiador colombiano presenta un recorrido por la producción historiográfica en la Nueva Granada y anota que a partir de 1782 se superó la visión escolástica y tradicional" ${ }^{15}$. Melo dedica unas páginas a la primera república y señala que Francisco José de Caldas y Joaquín Camacho, en su Diario Político de Santafé de Bogotá expresan la idea de estar viviendo una "época histórica" y aparece la noción de historia "como proceso que se hace" y el uso de su narración "para excitar la sensibilidad patriótica [y] como elemento de acción política"16. Al referirse a la prensa del período 1810-1816 afirma que en ella abundaban alusiones a los "fastos de la historia", al "juicio de la posteridad" y los protagonistas de los hechos "sentían" estar viviendo un momento histórico memorable ${ }^{17}$. Luego se refiere a la inclusión de la historia en el plan de estudios

12 Armando Martínez Garnica, "La Independencia del Nuevo Reino de Granada. Estado de la representación histórica" [en Manuel Chust y José Antonio Serrano (Eds.), Debates sobre las independencias iberoamericanas, Madrid, Ahila, Iberoamericana, Vervuert, 2007], p. 201-220.

${ }_{13}$ Catalina Reyes Cárdenas, "Balance y perspectivas de la historiografía sobre Independencia en Colombia", Historia y Espacio, No. 33, julio-diciembre 2009, p. 17.

14 Jorge Orlando Melo, "La literatura histórica en la República", Historiografia colombiana. Realidades y perspectivas, Medellín, Seduca, 1996, p. 46.

15 Jorge O. Melo, "Historia. Colombia" [en Javier Fernández Sebastián (Dir.), Diccionario político y social del mundo iberoamericano. La era de las revoluciones, 1750-1850, Madrid, Fundación Carolina, 2009], p. 616.

${ }^{16}$ Ibid., p. 621.

17 Ibid., p. 622.

Araucaria. Revista Iberoamericana de Filosofía, Política y Humanidades, año 19, n 38. Segundo semestre de 2017. Pp. 393-417. ISSN 1575-6823 e-ISSN 2340-2199 doi: 10.12795/araucaria.2017.i38.18 
de 1820 y, analiza con lujo de detalles las obras de José Manuel Restrepo, Joaquín Acosta y José María Samper, concluyendo de esta manera su estudio.

Como puede verse, con excepción de los aportes de algunos estudios historiográficos realizados por Germán Colmenares, Catalina Reyes, Sergio Mejía, Daniel Gutiérrez y Jorge Orlando Melo, no ha habido esfuerzos sistemáticos de investigación en torno al concepto "historia", la conciencia histórica de los neogranadinos y las nociones de historicidad en el tránsito de la Colonia a la República. Salvo los aportes de Melo y algunos hallazgos de éste en la prensa del período de la Independencia, es poco lo que se ha avanzado en tal sentido ${ }^{18}$. Para contribuir al conocimiento de esta problemática, el presente artículo pretende dar nuevas luces, presentar evidencias discursivas y proponer análisis que permitan comprender la conciencia histórica de los neogranadinos entre 1810 y 1827.

\section{Nueva percepción del tiempo y de la historia}

Para pensar los discursos de la prensa y otras fuentes documentales halladas en esta investigación se toman como punto de partida los planteamientos de Reinhart Koselleck sobre el cambio conceptual y la nueva percepción del tiempo que experimentó Occidente entre fines del siglo XVIII y comienzos del XIX. Este autor señala cómo a partir de 1789 el concepto "revolución" abarca las conmociones violentas de una sublevación que provoca cambios políticos profundos y la trasformación estructural de largo plazo que engloba todos los ámbitos y conduce a un futuro mejor y "la revolución adquirió el carácter de necesidad histórica”, a cuyo impulso era obligación consagrarse ${ }^{19}$. Además, se debe agregar el cambio en la percepción temporal, luego que la expectativa cristiana del fin del mundo perdió su carácter de presente continuo ${ }^{20}$. En otras palabras, surge una visión perspectivista del tiempo, plena de esperanza y de nuevos futuros posibles, que dan forma a nuevos pasados. La mirada que tiene su perspectiva en el futuro ve a éste como algo por crear, mientras que, al volverse al pasado en tanto cosa perdida, sólo ubica a este en el campo de lo cognoscible, y ambas miradas se separan cada vez más ${ }^{21}$. Así pues, lo que diferencia a los hombres modernos de sus antepasados es su forma de relacionarse con el tiempo.

\footnotetext{
${ }^{18}$ Francisco A. Ortega Martínez y Alexander Chaparro, (Eds.) Disfraz y pluma de todos. Opinión pública y cultura política, siglos XVIII y XIX, Bogotá, Universidad Nacional de Colombia - University of Helsinki, 2012.

${ }_{19}$ Reinhardt Koselleck, Historia de conceptos. Estudios sobre semántica y pragmática del lenguaje político y social, Madrid, Trotta, 2012, pp. 161-164.

${ }^{20}$ Reinhardt Koselleck, Futuro pasado. Para una semántica de los tiempos históricos, Barcelona, Paidos, 1993, p. 301.

${ }^{21}$ Reinhart Koselleck, historia/Historia, Madrid, Trotta, 2004, p. 126.
} 
Javier Fernández Sebastian se refiere a esta nueva percepción del tiempo, que avanzó en el mundo occidental de la mano de la filosofía ilustrada del progreso a fines del siglo XVIII y primeras décadas del XIX, e indica que la historia empezó a ser percibida como una realidad "producida en cierta medida por los seres humanos"22. Esta nueva forma de concebir la historia se manifestó en diferentes discursos, en el caso español, a partir de la primavera de 1808, con las sublevaciones contra la invasión napoleónica, y en la América hispana, con la formación de juntas autónomas entre 1809 y 1811. Según este autor, son numerosas las alusiones en la documentación histórica a una sensación de aceleración, cambio revolucionario e incertidumbre que deja sin lugar a la historia magistra vitae. No obstante, Fernández muestra el solapamiento entre ambos conceptos, ya que, en forma simultánea, se escuchan voces que descreen de las enseñanzas de la Historia y otras que confiaban en la sabiduría de los tiempos pasados ${ }^{23}$.

Debe señalarse que los discursos que se analizan en este artículo son expresión de un sujeto particular: el criollo letrado, que, en palabras de Gilberto Loaiza, fue el principal beneficiario del proceso de Independencia de las colonias hispanoamericanas. Un sujeto más o menos "ilustrado", caracterizado por su ambigüedad euro-americana, por considerarse la "nobleza" del nuevo mundo y protagonista indiscutible de la formación de la república. Este sujeto se transforma de súbdito de la corona española en ciudadano colombiano, parte de una minoría muy activa en la política que considera a la ley como principio ordenador de la sociedad y se dedica a la formación de opinión pública mediante la fundación de periódicos y la colaboración escrita y regular en la prensa ${ }^{24}$.

En el período comprendido entre 1810 y 1815 , en el que se inicia esa revolución conceptual en la Nueva Granada, dichos letrados tomaron conciencia de que la crisis de la monarquía española obligaba a los americanos a reasumir la soberanía y a formar juntas autónomas provinciales para salvaguardar la unidad territorial del virreinato. Nuevas circunstancias los llevaron a resolver sobre la marcha problemas relacionados con el gobierno, la división de poderes, la economía y la organización de ejércitos para la defensa de los nacientes estados que surgieron en las provincias neogranadinas. Por ello, desde muy temprano, aparecen constituciones republicanas y pro-monarquistas, como formas de resolver el problema en torno al vínculo social. Como dice Isidro Vanegas, esta vez, las constituciones son la expresión de la libre voluntad de los asociados

22 Javier Fernández Sebastian, "Revolucionarios y liberales. Conceptos e identidades políticas en el mundo atlántico" [en María Teresa Calderon y Clement Thibaud (Coords.) Las revoluciones en el mundo atlántico, Bogotá, Universidad Externado de Colombia, Taurus, Fundación Carolina, 2006], p. 219.

${ }^{23}$ Ibid., p. 221.

${ }^{24}$ Gilberto Loaiza Cano, "El criollo: de súbdito a ciudadano" en Gilberto Loaiza Cano y Maira Beltrán (Eds.), Ensayos de historia cultural y política: Colombia, siglos XIX y XX, Cali, Universidad del Valle, 2012], pp. 153 y ss.

Araucaria. Revista Iberoamericana de Filosofía, Política y Humanidades, año 19, n 38. Segundo semestre de 2017. Pp. 393-417. ISSN 1575-6823 e-ISSN 2340-2199 doi: 10.12795/araucaria.2017.i38.18 
y empiezan a instaurar una nueva forma de gobierno, de donde resulta "el dislocamiento del imperio del pasado sobre el presente, de la tradición sobre la innovación, que había caracterizado a la sociedad monárquica" ${ }^{25}$.

En tanto formadores de opinión, los criollos letrados expresaron ideas que permiten constatar la simultaneidad de dos regímenes de historicidad durante el período de estudio. De un lado, se encuentran incontables reiteraciones de una historia providencialista, que concibe el pasado como una sombra que se proyecta sobre el presente y el futuro y como fuente de lecciones y paradigmas para la praxis de los agentes históricos. Un primer ejemplo es el siguiente pasaje del periódico Aviso al Público, de octubre 6 de 1810, dedicado a cuestionar la legitimidad del Consejo de Regencia e invitar a los americanos a desobedecer sus mandatos. La experiencia histórica como fuente de autoridad, veamos: "Para probar los tales males pretéritos nos valemos de la historia. Para anunciar los futuros alegamos la previsión de los políticos, y las advertencias que nos había hecho la junta central"26. La historia, además, como conocimiento que constata las experiencias para aprender de los errores del pasado.

También en los primeros números de la Bagatela de Nariño se encuentran alusiones concretas a la historia como fuente de experiencias aplicables al presente. Un primer ejemplo es la epístola intitulada "El Filósofo sensible a una Dama su amiga", en el que defiende los logros de la vida republicana frente a quienes denigraban las libertades alcanzadas. Como recurso retórico, Nariño dice: "Así la historia de los siglos es en esta parte la historia de un solo día, y todos sus anales y sus fastos el eco repetido de la voz que forma siempre la naturaleza dentro de nosotros" ${ }^{\text {"27 }}$. Habría, por tanto, una razón histórica y natural para valorar los logros de la independencia política en la Nueva granada, y agrega otro elemento: la religión. Veamos: “¡Tan unidas están en esta parte la Religión y la Naturaleza! ¡Tan cierto es que no puede ser verdadero Cristiano, el que no es un buen Patriota!"28. El mismo tipo de argumentos para defender la Independencia aparecen en la "Carta a un amigo", en el que Nariño echa mano de experiencias recientes para él, en este caso la independencia de los Estados Unidos, como muestra del error que podría cometer España en caso de oponerse a la Independencia de los americanos:

"Que la España, si Dios le da vida, reconozca de buena fe nuestra INDEPENDENCIA, y entonces si seremos verdaderos amigos: la amistad sólo la puede haber entre hombres libres, y jamás entre los amos y los esclavos. Los ingleses no se han arrepentido, sino de haber hecho la guerra a sus Colonias; jamás han tratado de volverlas a subyugar, y es constante que les han producido

\footnotetext{
${ }^{25}$ Isidro Vanegas Useche, El constitucionalismo fundacional, 2a ed., Bogotá, Plural, 2014, p. 19

${ }^{26}$ Aviso al público, No. 2, Bogotá, octubre 6 de 1810, p. 6.

27 "El Filósofo sensible a una Dama su amiga", La Bagatela, No. 4, Santafé, Domingo 4 de agosto de 1811, p. 16.

${ }^{28}$ Ibídem.
} 
más ventajas como amigos, que como Colonos: y aun cuando esto no fuera, no lo han perdido todo, como sucedería a España si viviendo se obstinara en querer sostener el sistema Colonial, bajo las apariencias de partes integrantes"29.

Daniel Gutiérrez Ardila aporta ejemplos de la Primera República que refuerzan esta forma de concebir la historia como un "destino inexorable", un devenir sometido a una especie de ley, constatado por la supuesta existencia de un "ciclo inmemorial en virtud del cual las colonias se convertían en naciones y éstas a su vez en nuevas metrópolis" ${ }^{" 30}$. Este hallazgo en un periódico santafereño de 1811, presenta un panorama de la historia universal donde dicho ciclo se cumple en el antiguo Egipto, Grecia, Roma, Francia, España y Haití, de donde resultaba que los pueblos americanos estaban destinados a emanciparse. Este mismo pensamiento fue sostenido en 1814 por Jorge Tadeo Lozano:

\begin{abstract}
"Cuando levanto los ojos hacia todas las Naciones del mundo, y las veo siendo primero Colonias, y después figurando en calidad de Estados independientes de sus respectivas Metrópolis, entonces no puedo menos sino exclamar así: ¿Y porque los Americanos no podremos ser lo mismo, haciendo iguales esfuerzos? En efecto, este pensamiento no es ilusorio, sino muy verdadero y fundado en unos hechos constantes" ${ }^{31}$.
\end{abstract}

Pero no es posible afirmar que esta visión de la historia haya sustituido a concepciones heredadas del antiguo régimen. Más bien, coexisten ambas y sirven de argumento según las circunstancias, o adoptan connotaciones nuevas. Según Óscar Almario García en Occidente coexistieron distintas concepciones históricas del tiempo, desde las cíclicas heredadas del paganismo, pasando por las judeo-cristianas sobre un tiempo lineal y sagrado, hasta las ideas burguesas seculares de una progresión evolutiva. Al avanzar el siglo XIX se impone el tiempo secular de la modernidad, que instituye una representación hegemónica, universal, y única de la historia, en donde se articulan las distintas experiencias humanas. Pero, en el caso latinoamericano, el proceso que condujo a la irrupción de este tiempo "secular" de la modernidad, contó con ritmos propios y se produjo como parte "del proyecto de la modernidad política bajo los principios republicanos", e implicó la superposición de otras formas de percepción del tiempo ${ }^{32}$.

29 "Carta a un amigo", Suplemento a La Bagatela No. 4, Santafé, Domingo 4 de agosto de 1811, p. 2.

${ }^{30}$ Daniel Gutiérrez Ardila, Un nuevo reino. Geografia política, pactismo y diplomacia durante el interregno en Nueva Granada (1808-1816), Bogotá, Universidad Externado de Colombia, 2010, p.107.

31 Ibid., p. 108.

32 Óscar Almario García, "Continuidades y cambios en la percepción del tiempo, los acontecimientos y los imaginarios políticos durante la independencia neogranadina" [en Yobenj Aucardo ChicanganaBayona y Francisco Alberto Ortega Martínez (Eds.), 200 años de independencias. Las culturas politicas y sus legados, Medellín, Universidad Nacional de Colombia, 2011], pp. 21-22. 
A comienzos de 1816, cuando los ejércitos de Morillo avanzaban triunfantes por suelo venezolano, el Argos de la Nueva Granada informó lo ocurrido y reflexionó: "Tan cierto es que la constancia, la magnanimidad en los grandes conflictos, y un amor sincero y puro a la Independencia, es lo que redime, tarde o temprano, a un pueblo que pelea por este supremo bien. La historia de todos los tiempos confirma esta verdad que ha venido a ser axioma en la ciencia política"33. Se trata de una historia axiomática, que provee de verdades para dilucidar las leyes de la política y da la razón a la causa independentista. Esto permite plantear el desplazamiento de la historia magistra vitae a una historia que brinda bases factuales a la ciencia política. En la última entrega de las noticias sobre la reconquista en Venezuela, se explicita mejor lo dicho:

\begin{abstract}
"Conocemos que todos estos errores [aquellos que propiciaron el triunfo de Morillo] pueden sorprender al ánimo más fuerte, y al corazón más generoso; pero la historia, que en el sentir de Plutarco es la que forma los políticos y los hombres de Estado, o como quieren Maquiavelo y Folard, es la misma política puesta en práctica por hechos aplicados a los preceptos, debe servirnos de un preservativo para meditar nuestras deliberaciones en la salvación de la patria" 34 .
\end{abstract}

Este tipo de reflexiones en torno a la historia estaba motivado por los sucesos del momento, ya que ante el vértigo producido por la aceleración del tiempo -donde sucedían incontables eventos en el transcurso de pocos días, incluso en cuestión de horas- una actitud comprensible fue buscar entenderlos en comparación con situaciones similares del pasado. Para constatar este cambio en la percepción del tiempo, producto no de una sensación subjetiva sino de la experiencia diaria, valga comparar dos momentos de la prensa neogranadina. Como punto de referencia es del caso recoger lo dicho por Renán Silva Olarte en su libro Prensa y revolución a finales del siglo XVIII, donde analiza el despertar cultural vivido por la capital neogranadina, del cual hizo parte la publicación de El papel periódico de Santafé de Bogotá, entre 1791 y 1797. Este semanario, que llegó a 265 números, con una relativa amplia difusión en las principales ciudades del virreinato, que incidió en la dinámica de las tertulias, fue el germen de la opinión pública, "como también -en palabras del autor- parece haber sido un punto de concentración, expresión y dispersión

\footnotetext{
33 "Noticias americanas. Continúa la relación de los sucesos de Venezuela", Argos de la Nueva Granada, No. 107, Domingo 7 de enero de 1816, p. 637, [Tomado de Correo de la Nueva Granada No. 13] Cursivas en el original.

${ }^{34}$ El segundo de los nombrados es Jean Charles Chevalier Folard (1669-1752), autor de Comentarios sobre Polibio, un texto sobre el historiador griego Pausanias y obras sobre el arte militar, entre otras: Memoir on the progress of military discipline y Nouvelle découvertes sur la guerre. "Noticias americanas. Concluye la relación de los sucesos de Venezuela", Argos de la Nueva Granada, No. 108, Domingo 14 de enero de 1816, p. 641, [Tomado de Correo de la Nueva Granada No 13].
} 
de referencias sobre asuntos y noticias que entroncaban con las urgencias que el siglo venía fabricando"35. Pero apenas empezaba el despertar, ya que las ciudades donde circuló este "papel" experimentaban un tiempo ralentizado, fraccionado por las campanadas de las iglesias y las mayores conmociones, ocurrían los días de mercado.

\section{Del semanario al diario}

Por contraste, a partir de 1810 la incertidumbre sobre el presente y lo porvenir era cosa de todos los días. Almario García plantea, acorde con los fundamentos teóricos de este artículo, que el tiempo lento fue trastocado a partir de la "situación revolucionaria" y esto condujo a la percepción colectiva de que las cosas estaban cambiando en forma rápida. Almario muestra cómo los impresos de la época dan cuenta de los cambios en el ritmo cotidiano de la vida social y las nuevas percepciones del tiempo ${ }^{36}$. La documentación revela que los rumores sobre lo sucedido en España eran incontables; que la celeridad con que se daban los acontecimientos en la península ibérica y en las ciudades y villas del mundo hispanoamericano provocaba una avalancha de noticias contrapuestas, informes sobre sublevaciones, conmociones sociales y políticas, guerras civiles, desplazamiento de tropas y muchas otras situaciones. Además surgieron nuevas formas de sociabilidad entre criollos, indígenas y esclavos, $\mathrm{y}$, con la multiplicación de estados soberanos, organizaciones y "partidos" proliferó la publicación de periódicos, hojas sueltas y volantes. Al respecto, afirma Óscar Almario que la aceleración del tiempo y sus concomitancias contribuyó a "la irrupción y formación de sentidos diferentes, o por lo menos modificados, acerca de la época, que a su turno incidieron en la redefinición de las identidades de los diferentes grupos sociales y étnicos, aunque desde distintas escalas de percepción y conciencia" 37 .

$\mathrm{Y}$ aunque es indudable que muchos criollos ilustrados y formadores de opinión mantuvieron su mirada en el pasado o apelaron a sus conocimientos históricos para tratar de entender lo que estaba sucediendo, es notorio en la prensa de la época una mayor atención al presente tumultuoso -para dejar registro de la avalancha de sucesos político-militares- y cada vez fue más frecuente la exposición de visiones del futuro colectivo. Un primer elemento a tener en cuenta es la proliferación de medios noticiosos que trataban de fijar en el tiempo, mediante relatos detallados, lo sucedido cada día, incluso durante el transcurrir mismo del día, y esto llevó a la aparición de los primeros

\footnotetext{
${ }^{35}$ Renán Silva Olarte, Prensa y revolución a finales del siglo XVIII, Medellín, La Carreta, 2004, p.21-26.

${ }^{36}$ Óscar Almario García, "Continuidades y cambios en la percepción del tiempo... p. 25

${ }^{37}$ Ídem.
} 
diarios. Entre los primeros medios de este tipo se debe destacar el Boletín de Noticias del Día, que se empezó a publicar en Santafé como complemento de la Gaceta Ministerial de Cundinamarca, en cuyo proemio se lee: "A fin de que este público sepa las noticias interesantes, al momento en que llegan a esta Capital, sin la retardación que es consiguiente a la formación de una Gaceta Extraordinaria" 38 .

Valga decir que las primeras noticias publicadas en dicho boletín fueron dos oficios procedentes de la villa de Chiquinquirá, referentes a un combate ocurrido allí el día anterior. Por lo cual es de suponer que, muy en la madrugada, partió a todo galope un posta con dichos oficios, y luego de ser conocidos por el gobierno, pasaron a imprenta para hacerlos de conocimiento público. El sentido de inmediatez y de que la información debe circular sin pérdida de tiempo queda reflejado además en uno de los oficios publicados: "Ahora que son las cinco y media de la tarde, ha llegado una posta que viene del Puente de Guillermo y verbalmente nos impone de que desde las diez de la mañana de este día se rompió el fuego [...]"39. Se llegaba hasta el extremo que el destinatario de los oficios publicados en la prensa precisaba la hora en que redactó sus palabras: "Sitio y Cuartel General del Monte del Moro a las 7 de la mañana del día 21 de enero de 1812 " 40 .

Actitudes semejantes sobre el tiempo se observan en el Boletín de Providencias del Gobierno de Cundinamarca que, en su primer número, del 3 de febrero de 1813, informó que dicho día se plantó el árbol de la libertad. Nótese que se publica el mismo día que se hizo tal acto: "Habiendo amanecido hoy en esta ciudad plantado el Árbol de la Libertad en la Plaza Mayor"41. Debido a la poca asistencia de testigos, se analizó que podría carecer de legitimidad, y se decretó retirar el árbol plantado aquél día y volver a plantar "este signo de la libertad de los Pueblos" el segundo día de pascua de resurrección, en un evento solemne donde se advierta su significado, para que los ciudadanos sepan lo que significan "estas novedades públicas" boletín nombró una comisión para hacer efectivo un empréstito decretado por el Colegio Electoral y dar a conocer al público los nombres de los designados, quienes debían reunirse el mismo día para comenzar a ejercer sus funciones ${ }^{43}$. Como puede verse había mucha urgencia, no había tiempo que perder, las gestiones debían hacerse de inmediato, no dejando para mañana...

${ }^{38}$ Boletín de Noticias del Día, No. 1, Santafé, 23 de enero de 1812. Es de observar que este papel no se publicaba diariamente, sino cuando las noticias lo ameritaran.

39 Ibid.

40 Ibid.

${ }^{41}$ Boletín de Providencias del Gobierno, No. 6, Santafé, Imprenta del Estado, 3 de febrero de 1813.

Es un boletín de media página, con el sello del gobierno y sólo contiene esta noticia.

42 Ibid.

43 Ibid. 
Es el mismo tipo de conceptos que se encuentran en otros periódicos neogranadinos, como Década, un medio aparecido en 1814 en Cartagena, cuyo mismo nombre alude al asunto temporal y que en su preámbulo muestra la conciencia del tiempo agitado que vivían los ciudadanos: "Pues en unas revoluciones tempestuosas, en que todos miden sus operaciones con la ansiedad [...] se acredita la importancia de este papel" ${ }^{\prime 4}$. Los editores declaran sus principios, que se pueden resumir en los siguientes puntos: 1) Difundir principios, nociones, pensamientos y conocimientos; 2) Formar una colección de información con las mil noticias y los mil discursos de cada día; 3) Ofrecer sus páginas a los ciudadanos para que publiquen sus noticias y opiniones; $\mathrm{y}$, en sus palabras, 4) "Si nuevos acontecimientos pasan, y otros suceden tales como ellos fueren los publicaremos". Pero no se trataba sólo de informar los sucesos de las provincias de la Nueva Granada, sino de América y las naciones extranjeras, "prefiriendo las que tengan relación con nuestra transformación política, y prosperidad general”45. Y sus 18 ejemplares y 166 páginas dan buena cuenta de ello.

El repertorio de palabras usado en aquellos diarios y boletines está relacionado con un tiempo sincrónico que da cuenta de las acciones que se ejecutan en el instante mismo en el que se enuncian o, por lo menos, en un transcurso de tiempo inmediatamente posterior a su enunciación, en lapsos de horas o días. Ejemplo de ello es el antes citado boletín cundinamarqués, que menciona una situación de "inminente peligro", ante la cual el gobierno debía "apurar cuantos medios", y ordena que "inmediatamente" se forme una Compañía de Forasteros, cuyos reclutas "debían estar prontos a marchar para Popayán en toda la próxima semana" ${ }^{46}$. Otra providencia enunciada por el mismo medio muestra que el nuevo sentido del tiempo implicaba que, por tratarse de un recurso finito e irrecuperable, el gobierno debía velar por su aprovechamiento. Se trata de una medida contra el abuso del juego entre los habitantes santafereños, y entre sus argumentos alude a "la distracción de los ciudadanos en un tiempo en que la patria exige imperiosamente el empleo del tiempo en su auxilio y defensa" ${ }^{47}$. Los castigos a quienes frecuentaran o fueran dueños de garitas o casas de juego eran drásticos, e iban desde multas considerables, decomisos, prisión y trabajo en obras públicas por un mes.

Una de las formas de evidenciar las perspectivas de futuro de los neogranadinos son las innumerables cartas constitucionales que aprobaron los estados provinciales y la del Congreso de las Provincias Unidas. La prensa también es muestra de este interés: "Tenemos ya convocados todos los

44 “Prospecto”, Década. Miscelánea de Cartagena, No. 1, Cartagena, Septiembre 29 de 1814, p. 1.

${ }^{45}$ Ibíd., pp. 1-4.

${ }^{46}$ Boletín de Providencias del Gobierno, No. 10, Santafé, Imprenta del Estado, 10 de julio de 1813.

${ }^{47}$ Boletín de Providencias del Gobierno, No. 3, Santafé, Imprenta del Estado, 20 de febrero de 1812. Esta disposición fue tomada por el presidente de Cundinamarca Antonio Nariño. 
Pueblos para que, reasumiendo todos sus derechos en el Colegio Electoral por medio de sus apoderados, realicemos y ratifiquemos la Unión y Obediencia a la Constitución y Supremo Gobierno de esa ilustre Provincia [...]"48. En el preámbulo de los textos constitucionales no faltan alusiones a la búsqueda de la felicidad, tranquilidad y disfrute de libertades de los habitantes de la respectiva provincia. El uso de los verbos tiene una función notoria: se trata de hacer presente lo que se desea lograr en el futuro, comprometiendo a los poderes públicos y a la ciudadanía en general para su realización. Por ello se usan el presente (adopta, ratifica, reconoce, profesa, garantiza...) y el futuro en sus diferentes formas: habrá, deberá, permitirá, adoptará (futuro imperfecto) y se llega a planear el uso del tiempo venidero, definiendo plazos para ciertas tareas o metas. Verbigracia, cuando se concede un mes para que los tres poderes resuelvan un punto en disputa, y se reglamenta el uso del tiempo futuro: "Pasado este tiempo, procederá cada uno de los tres poderes por separado a formalizar su votación"49. De hecho, una de las funciones de la carta política fue definir las acciones a emprender por parte de funcionarios y ciudadanía.

Esta suerte de conjuración de los peligros a través de la palabra, que se manifiesta en las constituciones de la época, tiene además otro aspecto importante: mediante la aprobación y ratificación de los pueblos que le dan legitimidad, se compromete la acción futura, como quedó explícito en el "Acta de federación de las Provincias Unidas de la Nueva Granada": "Prometen asimismo todas ellas, que concurrirán al bien universal, haciendo sacrificio de sus intereses particulares, cuando la reserva de ellas pudiera ser perjudicial al bien común, prefiriendo este en todo evento al suyo propio, y mirando al gran pueblo de la Nueva Granada en todas sus provincias, como amigos, como aliados, como hermanos y como conciudadanos" ${ }^{50}$. Con el mismo propósito, varias constituciones definieron el juramento que debían llevar a cabo los funcionarios públicos al momento de su posesión. Sólo a modo de ilustración se citan las palabras que debían rezar los funcionarios del estado antioqueño de 1812: "Juro obediencia y fidelidad al Estado de Antioquia, observar y hacer observar su Constitución, cumplir fielmente las obligaciones que me incumben como (aquí el nombre del empleo), según mis talentos e inteligencia"51.

${ }^{48}$ Boletín de Noticias del Día, No. 7, Santafé, 18 de Febrero de 1812, p. 2

49 "Constitución de Cundinamarca, [Santafé de Bogotá, Imprenta patriótica de D. Nicolás Calvo y Quijano, 1811] en Manuel Antonio Pombo y José Joaquín Guerra, Constituciones de Colombia, Bogotá, Ministerio de Educación Nacional, 1951, Tomo 1, p. 136

50 "Acta de federación de las Provincias Unidas de la Nueva Granada", Manuel Antonio Pombo y José Joaquín Guerra, Constituciones de Colombia, Bogotá, Ministerio de Educación Nacional, 1951, Tomo 1, p. 212.

51 "Constitución del Estado de Antioquia", [Santafé de Bogotá, Imprenta de Bruno Espinosa, 1812], p. 347. 


\section{Libertad de imprenta y desaceleración del tiempo}

Luego del período de la Reconquista (1815-1819), cuando la mayoría de criollos que estuvieron al frente de los procesos de la primera república fueron pasados por las armas y ajusticiados en juicios sumarios, mientras que otros huyeron hacia los llanos venezolanos a refugiarse y preparar la contraofensiva, fue notorio el retroceso en cuanto a la publicación de prensa en la Nueva Granada. Y al silenciarse las imprentas se pierde la pista sobre las nociones de historicidad y temporalidad que hacían parte del utillaje mental de los neogranadinos. Empero, consolidada la Independencia, luego del triunfo de los ejércitos comandados por Bolívar en Boyacá y el centro de la Nueva Granada, con la expedición de la Constitución de la República de Colombia en 1821 volvió a desarrollarse la publicación de medios impresos. Según el historiador Juan David Murillo, el nuevo marco jurídico y constitucional amplió el campo de lo impreso, reglamentó y dinamizó la producción y circulación de libros, periódicos e impresos de todo orden ${ }^{52}$.

Entre los principales rasgos de la prensa de la década de 1820 se destaca que su periodicidad es muy irregular y que son inexistentes -en el universo incluido en esta pesquisa- los diarios, predominando los semanarios, quincenarios; otros medios tuvieron una periodicidad que variaba entre tres, cuatro, cinco y siete días. Además, eran en su mayoría periódicos de corta duración, que combinaban información sobre los actos de gobierno, las leyes aprobadas por el Congreso, las noticias, las columnas de opinión y las cartas al redactor, que en varias ocasiones desembocaron en interesantes polémicas. Estas dos últimas categorías aportaron al análisis, por tratarse de la expresión fidedigna de los ciudadanos, y permite conocer de primera mano las nociones del régimen de historicidad en ciernes.

Una prueba de la importancia que en la prensa republicana se le siguió dando al conocimiento histórico como fuente de sabiduría política en el contexto de los nacientes estados iberoamericanos es la reproducción de extractos tomados de obras historiográficas del momento. Pero como es lógico, lo que se publica es una interpretación hecha por quien traduce, resume y define los apartes que se dan a la luz pública. Es el caso de una columna que, bajo el título de "Variedades", se publicó en el Correo de la Ciudad de Bogotá en febrero de 1822, reflexiona en torno al papel que cumple históricamente la oposición, y

\footnotetext{
${ }^{52}$ Este autor señala que para 1819 en la Nueva Granada escaseaban las imprentas, el papel y las tintas, así como la mano de obra especializada en el ramo de la impresión. La ley del 27 de septiembre de 1821 liberó de derechos de importación a los artículos relacionados con esta actividad, e inició un despertar de las imprentas, pero, aún en 1823, apenas había dos periódicos en Bogotá. Fue a partir de 1825 que se constata un segundo auge de las imprentas y la proliferación de periódicos en Colombia. Juan David Murillo Sandoval, "El Estado como librero. Políticas oficiales y cultura impresa en Colombia, 1821-1886", [en Alfonso Rubio (Ed.) Minúscula y plural. Cultura escrita en Colombia, Medellín, La Carreta, 2016], pp. 273-276
} 
afirma que, en los estados libres, ésta consiste en la defensa de la Constitución, las leyes y la conservación de la libertad, pero que la naturaleza de los gobiernos determina la función, poder y medios de la oposición; pasa a hacer un análisis de distintos casos, para lo cual acude a las experiencias históricas de la época moderna, a saber, cómo actúa la oposición en los estados despóticos, en las monarquías representativas y en los estados libres, y concluye:

\begin{abstract}
"Es pues cierto [...] que todo poder humano, aún el más absoluto despotismo experimenta alguna resistencia. [...] En los pueblos modernos que tuvieron antes Constituciones y que hoy conservan leyes que sólo obligan al pueblo, donde el Poder Ejecutivo ha degenerado en dominación arbitraria, las costumbres, la religión, los tribunales superiores, las luces, una cierta fuerza de inercia producen una oposición lenta; pero cierta. Todas las revoluciones de los últimos siglos han tenido su origen en esta especie de oposición" ${ }^{\text {33 }}$.
\end{abstract}

Como puede verse, se trata no ya de la historia magistra vitae, sino de la pretensión de hacer ciencia política con fundamentos históricos, para establecer conocimientos generales que permitan entender mejor el presente, en este caso, el lugar de la oposición en un gobierno republicano. Es coherente este concepto con otro expuesto algunas líneas antes, que el futuro no se espera, sino que se construye desde la praxis y desde las decisiones que conducen a su alumbramiento. Por ello no es de extrañar que el mismo periódico en otro de sus números afirme que le corresponde a ciertos individuos, héroes u hombres de estado, forzar a quienes se resisten a aceptar el dictamen de la historia en aquella época, a aceptar la libertad que otorgan las leyes: "Ved la ocupación y los talentos del héroe, que frecuentemente con la fuerza en la mano se pone en estado de recibir las bendiciones de los hombres a quienes obliga al principio a soportar el yugo de las leyes, para someterlos en fin a la autoridad de la razón" ${ }^{54}$.

Para entender el contexto de esta reflexión debe tenerse en cuenta que la Independencia era un hecho, habían transcurrido tres años y unos meses de la derrota de los ejércitos realistas en el puente de Boyacá y que la República de Colombia se había formado en 1821. Pero aún existían focos de rebelión en el sur, donde pastusos y patianos seguían resistiendo a las leyes republicanas; también en Quito se seguía esperando la restauración monárquica, y, probablemente quedaban algunos rescoldos realistas en Santa Marta, Panamá y otros sitios; además, por aquellos años, llegaban noticias de España sobre la intención manifiesta de organizar un nuevo ejército de reconquista, lo cual finalmente no fue posible por las restricciones del fisco. Es decir, que aún no estaba muy clara

53 "Variedades", extracto de "Essai sur la revolución de France", Correo de la Ciudad de Bogotá, No. 134, Jueves 21 de febrero de 1822, pág. 436-437. Lamentablemente no se pudo establecer el autor de este texto, ni es claro si se trata de un libro o un texto tomado de un periódico extranjero.

54 "Variedades", Correo de la Ciudad de Bogotá, No. 135, Jueves 28 de febrero de 1822, p. 440. 
la irreversibilidad del proceso independentista, y que, por cuanto lo conquistado no estaba garantizado por una ley inamovible de la historia, estaba en manos de los hombres su consolidación, y en este caso concernía a los hombres de estado defender el estado libre y soberano, aun por medio de la fuerza. Esta reflexión se publicó en la misma página que la proclama de Simón Bolívar a los patianos, pastusos y españoles de Quito, mediante la cual informa que el ejército colombiano estaba en camino a sus territorios y los invita a aceptar de buena manera hacer parte de "la familia colombiana" y "poner de acuerdo los intereses de todos los hermanos" $" 55$.

Ahora bien, era normal que algunos pueblos fueran acusados de traicionar la causa de la libertad y la república, motivo por el cual algunos de sus líderes y voceros debían salir a defender la imagen de su patria chica. Así le tocó a Tomás Cipriano de Mosquera en 1822, cuando al parecer eran frecuentes las acusaciones contra la ciudad de Popayán por su ambivalencia ante la disyuntiva de apoyar a los republicanos o a los realistas. Según una carta de Mosquera, dirigida al redactor de la gaceta bogotana antes citada, su ciudad natal había sido declarada "Ciudad enemiga a la Santa causa de Colombia". En su defensa, dice que sus compatriotas estaban escribiendo "Manifiestos que saldrán a la luz de la historia de sus acontecimientos, ellos la vindican, y lejos de resultar criminal aquel pacífico e inocente pueblo, se hace ver su adhesión al sistema liberal, y causa de su Patria" ${ }^{56}$. Para respaldar su argumento, Mosquera incluye un cuadro comparando el bajo número de payaneses realistas (que emigraron de la ciudad o fueron exiliados), con la superior cifra de quienes ocupaban puestos civiles o militares al servicio de la república.

Ante las quejas desmesuradas de los colombianos contra el gobierno de Santander, la prensa liberal, que asumió su papel como formador de ciudadanos, explicó a éstos que la instauración del pacto republicano no significaba "caminos anchos y sin malos pasos, y otros, colegios y muchas escuelas", como tampoco esperar todo del gobierno ${ }^{57}$. Y por ello explica que "La revolución lo ha cambiado todo, y la guerra ha contribuido a formar un carácter diverso en los hombres que la han sufrido"58. Procede a explicar a sus lectores que lo nuevo implica dificultades, experimentos y por tanto errores, y que se requiere una cierta manera de actuar de parte de todos, refrenando y corrigiendo pasiones y defectos. Y recuerda que ni los países europeos más avanzados habían logrado la perfección, por no ser parte de la condición humana, a pesar del aprendizaje que da la maduración del tiempo:

\footnotetext{
55 "Proclama. Simón Bolívar Libertador Presidente de Colombia... A los patianos, pastusos y españoles de Quito", Correo de la Ciudad de Bogotá, No. 135, Jueves 28 de febrero de 1822, p. 440.

56 Tomás Mosquera, [Carta firmada en Caloto, diciembre 16 de 1821] "Otro. Sr. Redactor de la Gaceta de Bogotá.” Correo de la Ciudad de Bogotá, No. 134, Jueves 21 de febrero de 1822, p. 439.

${ }^{57}$ Correo de la Ciudad de Bogotá, No. 136, Jueves 7 de marzo de 1822, p. 444.

58 Ibidem, p. 445.
} 


\begin{abstract}
"En ninguna parte del mundo se ha logrado la perfección de un sistema porque esto no es posible entre hombres. En Inglaterra donde se acerca más el sistema a la perfección han pasado muchos centenares de años para llegar a ese estado, se han sufrido muchas revoluciones, se ha derramado mucha sangre, y todavía se experimentan agitaciones turbulentas. Las rentas no se entablan de repente; esta es obra del tiempo, de las luces, y de los fondos que se apliquen a su mejora e incremento. Un pueblo como el de Colombia nuevo en la economía política, y entregado de preferencia a la guerra no puede establecer en uno, ni dos años su sistema de rentas $[\ldots]^{\prime 59}$.
\end{abstract}

Esta es una idea insistente en este y otros medios de la nación, y refleja un concepto de historia según el cual el progreso, la civilización y una proximidad a lo más excelso en gran medida es resultado de la acción humana, pero son frutos que resultan con la lenta maduración de los siglos ${ }^{60}$. Lo que se trasluce a fin de cuentas es la noción de "experiencia histórica" como un acumulado de aprendizajes que se encarna en la memoria de una sociedad y le permite avanzar en el camino de la civilización, pero en la larga duración. Este concepto de historia, ligado semánticamente a la idea de progreso y civilización, tiene como referentes o modelos no las lecciones de los antiguos, sino a aquellas naciones que se consideraban de avanzada al despuntar el siglo XIX, cuya cúspide es ocupada por Inglaterra, pero agrega que, siguiendo el ejemplo de ésta, los Estados Unidos estaban logrando ese estado ideal. Y no se niega la posibilidad de que Colombia algún día, con esfuerzo y dedicación, también lo pueda alcanzar. Valga decir que el artículo en mención considera que una prensa fuerte y libre contribuye al desarrollo económico, político, institucional, cultural y forma ciudadanos más pacíficos e ilustrados ${ }^{61}$.

No cabe duda que una nueva percepción del tiempo estaba ganando terreno en la opinión pública. Por ejemplo, algunos polemistas de prensa invitan a sus contrincantes a reflexionar sobre las diferencias que hay "de tiempo a tiempo"; a que se reconozcan las diferencias de la España anterior a la revolución y la España que resultó de aquella, y por último a "discernir los tiempos" 62 . Este tipo de ideas, expresadas bajo el seudónimo de "Cándido Justo Veritas", reflejan la visión de un tiempo discontinuo que todo lo cambia en el transcurso de unos años. También es una reflexión sobre el tiempo histórico y en torno a asuntos claves del pensamiento histórico, como el anacronismo y la concepción del tiempo como una repetición incesante o continuidad del mismo proceso. Al

59 Ibid., p. 445.

${ }^{60}$ En el No. 145 de Correo de la Ciudad de Bogotá, jueves 9 de mayo de 1822, pág. 480, se lee: "La Inglaterra por ejemplo, no ha adquirido la estabilidad que hoy nos admira, ni los ingleses han criado amor a su legislación sino después de muchos siglos, y de muy sangrientas revoluciones".

${ }^{61}$ Lo mismo plantea otro periódico colombiano: Correo del Magdalena, No. 3, Cartagena, jueves 26 de mayo de 1825 , p. 4.

62 "Sr. Don Fructuoso Belmonte", Correo de la Ciudad de Bogotá, No. 137, Jueves 14 de marzo de 1822, p. 451. 
mismo tiempo, la respuesta de otro colaborador del mismo semanario bogotano -quien inicia un cruce de artículos sobre el tema-, cuyo seudónimo es "Un Colombiano", también es interesante, ya que muestra, a partir de la experiencia reciente, cómo la historia sí puede enseñar a no repetir los errores del pasado, es decir, la historia magistra vitae con el mazo dando, pero no se trata de la experiencia ajena sino de la propia:

\begin{abstract}
"Se pronuncia Ud. Abiertamente contra el mantenimiento de una fuerza armada hasta juzgar por delirio el proyecto de mantenerla. Así mismo opinábamos el año de 1810, ateniéndonos a nuestros derechos imprescriptibles, al estado ruinoso de la nación Española, a su guerra con los Franceses, y a que todo Ciudadano era soldado nato de la Patria. Vino Morillo, y aunque tarde, nos hizo palpar cuan insensatos éramos, y con cuanta puerilidad habíamos calculado..." ${ }^{\prime 3}$.
\end{abstract}

La militancia del semanario bogotano queda más explícita luego de un cierre temporal que duró entre mayo y diciembre de 1823. El 26 de este último mes anunció su retorno, motivado por la circulación de "papeluchos sediciosos" que invitaban a volver a "la antigua servidumbre" ${ }^{64}$. Como respuesta a quienes se opusieran al sistema republicano expone que su línea editorial es contra ellos: "secretos adoradores del despotismo, con caras de humildes corderos y corazón de tigres [...] que día y noche suspiran por el antiguo régimen, que diariamente inventan expediciones y fraguan noticias para desalentar el espíritu público y para ver si nos empujan de nuevo en el abismo de la extranjera tiranía" ${ }^{\prime 65}$. No sobra añadir que los periódicos analizados acostumbran agregar al lado derecho del año en que se publica, entre paréntesis, los años transcurridos desde 1810, verbigracia: 1823 (13).

\title{
Las fuerzas que determinan la historia
}

Es interesante aludir a una columna reproducida por el semanario bogotano antes citado, tomada de un periódico de La Habana donde se plantean una serie de enunciados que permiten vislumbrar una forma particular de filosofía de la historia, que está en el trasfondo de aquella representación histórica. El autor de esta nota propone que el mundo no es gobernado por los grandes hombres, sino por las pasiones: "Según las diferentes épocas o circunstancias de los tiempos, ora ha dominado la pasión de la guerra, ora el ardor de las conquistas, o el amor

\footnotetext{
${ }_{63}$ "Sr. Don Cándido Justo Veritas", [Bogotá, marzo 16 de 1822] Correo de la Ciudad de Bogotá, No. 138, Jueves 21 de marzo de 1822, p. 453.

${ }^{64}$ Este periódico dejo de circular el 8 de mayo de 1823 y volvió a publicarse el 26 de diciembre del mismo año con el título Correo de Bogotá.

65 "Resurrección del Correo de Bogotá", Correo de Bogotá, No. 1, viernes 26 de diciembre de 1823, p. 1.
} 
de la libertad, o el respeto por las creencias antiguas, o el deseo de una reforma, o los principios e ideas liberales, o el espíritu de comercio e industria [...]"66. Es decir, el poder para cambiar la historia no reside en ciertas personas, sino en los conceptos dominantes en determinada época.

Conceptos que pueden tomar la forma de "opiniones e intereses" de mucha influencia, o que hacen tendencia, y los "grandes hombres" que lideran los cambios son aquellos que saben comprender su tiempo, es decir, en palabras del articulista, aquellos que saben "discernir y apreciar justamente la tendencia de aquellas opiniones e intereses, [para] dirigirlas con discreción y prudencia, y seguirlas con energía y constancia" ${ }^{97}$. Así, por ejemplo, fue el espíritu de venganza de los griegos ante los ultrajes de los persas lo que explica a Alejandro Magno: "Alejandro se presenta y se enuncia como este vengador, y crea una nueva época en la historia"68. Julio César fue la venganza de Roma contra las agresiones de los bárbaros. Por ello se llega al punto de restar valor a los llamados grandes hombres como hacedores de la historia, acotando su función a buenos intérpretes de las ideas u opiniones generalizadas ${ }^{69}$.

Por supuesto, se trata de una representación del pasado que tiene un trasfondo político y la intención clara de legitimar las transformaciones vividas en Occidente desde 1789, encontrando un sentido y razón histórica a la conquista de las libertades democráticas y por consiguiente dejando sin razón de ser al viejo régimen. De ahí que, a renglón seguido se añada lo siguiente: "Ahora pues, la tendencia universal, la opinión común y unánime de todos los pueblos de Europa, el interés y la convicción de todas esas masas inmensas las lleva hacia una libertad racional, apoyada en buenos códigos fundamentales y buenas leyes"70. Es de aclarar que esta interpretación tiene como sustrato filosófico una naturalización de la historia, es decir, se trata de un destino manifiesto, de un sentido infalible, al cual no vale la pena oponerse, y quien fuera tan necio sólo comprobaría que sus triunfos serían efímeros. Por ello el colofón de esta reflexión es la siguiente: "La naturaleza misma lo indica y lo exige, y la naturaleza no miente ni engaña jamás" "71.

Se trataba, aún, de tiempos esperanzados, cuando la figura del Libertador resultaba incontestable. En él muchos veían el mejor intérprete del siglo, quien actuaba según lo dictaba una supuesta racionalidad histórica. Esta visión cambió cuando las disensiones provocadas por las rebeliones de ciertos caudillos militares contra el gobierno de Santander, en diferentes partes del

66 "Diario del gobierno constitucional de La Habana No. 224", Correo de la Ciudad de Bogotá, No. 180, Jueves 9 de enero de 1823, p. 622.

${ }^{67}$ Ídem.

68 Ídem.

69 "Diario del gobierno constitucional de La Habana No. 224", Correo de la Ciudad de Bogotá, No. 180, Jueves 9 de enero de 1823, p. 622.

70 Ídem.

71 Ídem. 
vasto territorio de la Gran Colombia, hicieron aparecer negros nubarrones. Por ello, pocos años después, en 1826, la prensa anunciaba el avance, de norte a sur, de una terrible tempestad provocada por la insubordinación y el irrespeto a las instituciones y las leyes que "amagaba destruir en un momento la obra de tantas lágrimas y de tantos sacrificios" 72 . Hubo quienes vieron razones históricas en éstos hechos, porque no se trataba de individuos, sino de "la exigencia de las cosas y el curso de los tiempos". Según El Censor, la respuesta de los amigos de la constitución fue buscar y traer desde Perú al Libertador, y con cierta sorna opina: "Nuestros males serán curados y el genio del siglo obrará la felicidad de su patria" ${ }^{\prime 73}$. Pero se advierte a los lectores que este genio nada lograría sin el concurso de todos los ciudadanos, por lo cual el citado periódico, en varias de sus ediciones, pide a sus compatriotas rodear a Bolívar: "Los colombianos todos deben prestarle sus auxilios" $" 74$.

Pero pronto los mismos que pensaron que la cura a los males anunciados estaba en el Libertador empezaron a dudar de ello, así que el mismo periódico percibió el peligro de investir con poderes omnímodos a un solo ciudadano. El análisis de lo que estaba sucediendo es el siguiente: “[ ...] y por un movimiento simultáneo levantaron los más el grito, y proclamaron por Dictador al gran Bolívar su Libertador y su Padre. Desde este momento dejaron de pensar en división de poderes y en las otras garantías constitucionales"75. Declarada su postura a favor del gobierno representativo, el articulista señala el que considera como principal origen de sus males, a saber, la prevalencia de los intereses privados en cabeza de los congresistas y gobernantes, que repercute en el desprestigio de las instituciones: "La mayor parte de sus miembros sólo se han ocupado de sus propios intereses y de subordinar a sus miras el influjo, el poder, y hasta el honor que da la representación [...] Así, cada uno ha ganado, amén de sus dietas, alguna cosilla para medrar y pasar esta miserable vida; pero el comercio, la agricultura, las artes! ¿Qué beneficio han recibido?"76.

A medida que avanzaba el desprestigio del Congreso y el gobierno se incrementaron las rebeliones contra el gobierno y empezaron a formarse partidos en torno a Bolívar y Santander, y la prensa empezó a evidenciar y a alinderarse según su predilección por el gobierno constitucional o por la concentración de poderes en el Libertador. Ejemplo de ello es El bobo entretenido, un periódico bogotano aparecido en junio de 1827, cuyo lema era "Ser libres o morir", y que en su primer número analiza la situación de la nación y hace un ejercicio de jugar con un escenario de futuro posible en ese momento: 1) Bolívar insiste en su renuncia argumentando que no puede gobernar conforme a la constitución

\footnotetext{
72 "Prospecto", El Censor, No. 1, Bogotá, domingo 19 de noviembre de 1826, p. 1.

73 Ídem.

${ }^{74}$ Ibid., p. 4.

75 "Congreso", El Censor, No. 2, Bogotá, jueves 23 de noviembre de 1826, p. 1.

76 Ídem.
} 
de Cúcuta y el pueblo acepta que "nos gobierne por los siglos de los siglos"; 2) Para no oponerse a los designios del gran hombre, el Congreso acepta la Constitución Boliviana; 3) El partido constitucional es derrotado y convertido en "las bestias que han de tirar los carros de la nobleza"77. No obstante, acepta el dominical que sus pronósticos podrían no salir al pie de la letra, y en efecto no fue así. Lo interesante es constatar cómo los agentes históricos, en medio de sus encrucijadas políticas, construyen hipotéticos escenarios de futuro para decidir sus estrategias de acción en lo inmediato y lo mediato, incidiendo mediante sus decisiones en el curso del futuro e inclinando a su favor la balanza si la correlación de fuerzas está de su parte.

Lo cierto es que la dictadura bolivariana se hizo realidad en junio de 1828 , luego de la Convención de Ocaña, y esta produjo como reacción la conspiración septembrina y la rebelión del general Córdova en Antioquia; y luego, con la separación de Venezuela, llegó a su término la existencia de la Gran Colombia. Estos hechos han sido bien estudiados por la historiografía colombiana, pero para efectos de este texto interesa destacar cómo con dos años de anticipación los editores de este impreso pronosticaron su ocurrencia, a partir de un análisis correcto de la tendencia histórica, los actores decisivos, los factores internos y la correlación de fuerzas políticas y sociales.

\section{Conclusiones}

Los historiadores colombianos que se han ocupado de la producción académica sobre el período de la Independencia han tenido como referente fundamental la obra del historiador José Manuel Restrepo, como hito fundacional de la historiografía republicana, lo cual puede generar la idea equivocada de que la conciencia histórica es un asunto de personas dedicadas a este oficio. Por tanto, se puede caer en una idea según la cual corresponde a los historiadores la reflexión en torno al conocimiento histórico, su papel en la formación de los ciudadanos, sus coordenadas espacio-temporales, la forma adecuada de pensar la causalidad histórica y la relación entre pasado, presente y futuro. Este artículo, a partir de un rastreo sistemático de la prensa y de algunos textos constitucionales, permite patentizar una premisa de la conciencia histórica: que los ciudadanos en general elaboran unos parámetros para pensarse a sí mismos como parte de una historia colectiva, y por ello le resulta natural interpretar el pasado, tomar decisiones en el presente y avizorar lo porvenir.

Por supuesto, incluso los súbditos del antiguo régimen eran portadores de ciertas nociones de historicidad. Se pudo identificar que algunas de éstas se mantienen en el período estudiado y coexisten con conceptos propios de

77 “Renuncias", El Bobo Entretenido, No. 1, Bogotá, domingo 24 de junio de 1827, p. 1 
un nuevo régimen de historicidad y ambas se imbrican, chocan y se solapan. Entre fines del siglo XVIII y las primeras décadas del XIX comienza el tránsito hacia nuevos conceptos de la historia, el tiempo, la permanencia y el cambio, los límites de los agentes y el papel de lo nuevo. Así las cosas, era de uso común expresiones reiteradas de la historia magistra vitae, los cuales toman como paradigma los hechos de la Grecia antigua y la republica romana, incluso procesos más recientes de Europa y Estados Unidos. Más aún, se hallaron reelaboraciones modernas del concepto ciceroniano con base en experiencias históricas a partir de las cuales se piensa la posibilidad de construir un conocimiento científico de los problemas políticos de la modernidad, además de servir para proponer pautas de acción en el presente. También se encontró una reflexión intempestiva sobre las lecciones que la historia aporta al momento de tomar decisiones que afectan a toda la colectividad, tomando como ejemplo la experiencia de la Primera República, cuando se descuidó el aspecto de la organización de un ejército bien adiestrado y entrenado para defender las libertades alcanzadas al momento de reasumir la soberanía.

Pero también se observó en numerosos artículos de opinión y epístolas cómo se estaba configurando una forma de entender la historia como algo que se hace y se construye por la sociedad y los individuos. Es palpable la manera como se aceleró el tiempo después de 1810 y esto se manifestó en el lenguaje y en la necesidad sentida de publicar noticias de los acontecimientos en el mismo instante en que se daban. Tiempo de urgencia, presteza e inmediatez. Sorprenden conceptos de la historia como el resultado de una experiencia compartida, donde confluyen tiempos muy largos, que abarcan varios siglos $\mathrm{y}$ que son los que permiten a una colectividad humana acumular riqueza, conocimiento y madurez política y cultural para su perfeccionamiento. Pero que al mismo tiempo se modifica por la fuerza que adquieren ciertos conceptos, convertidos en opinión generalizada, para producir cambios. En la misma dirección los ciudadanos en tanto sujetos históricos indagaban los hechos y se atrevían a pronosticar, a la luz de las tendencias históricas y correlaciones de fuerzas, escenarios de futuro posibles, desde los cuales definir posturas en torno a los asuntos públicos y determinar el rumbo de su praxis, planeando acciones inmediatas y mediatas (táctica y estrategia). 


\section{Referencias bibliográficas:}

Almario García, Óscar. "Continuidades y cambios en la percepción del tiempo, los acontecimientos y los imaginarios políticos durante la independencia neogranadina", en: Yobenj Aucardo Chicangana-Bayona y Francisco Alberto Ortega Martínez (Eds.), 200 años de independencias. Las culturas políticas y sus legados, Medellín, Universidad Nacional de Colombia, 2011.

Betancourt Mendieta, Alexander. Historia y nación. Tentativas de la escritura de la historia en Colombia, Medellín, La Carreta, 2007.

Colmenares, Germán. Las convenciones contra la cultura, Bogotá, Tercer Mundo, 1989.

Fernández Sebastian, Javier. "Revolucionarios y liberales. Conceptos e identidades políticas en el mundo atlántico", María Teresa Calderon y Clement Thibaud (Coords.) Las revoluciones en el mundo atlántico, Bogotá, Universidad Externado de Colombia, Taurus, Fundación Carolina, 2006.

Gutiérrez Ardila, Daniel. Un nuevo reino. Geografia política, pactismo y diplomacia durante el interregno en Nueva Granada (1808-1816), Bogotá, Universidad Externado de Colombia, 2010.

- El reconocimiento de Colombia: Diplomacia y propaganda en la coyuntura de las restauraciones (1819-1831), Bogotá, Universidad Externado de Colombia, 2012

Koselleck, Reinhardt. Futuro pasado. Para una semántica de los tiempos históricos, Barcelona, Paidos, 1993.

Historia de conceptos. Estudios sobre semántica y pragmática del lenguaje político y social, Madrid, Trotta, 2012. . historia/Historia, Madrid, Trotta, 2004.

Loaiza Cano, Gilberto. "El criollo: de súbdito a ciudadano", en: Gilberto Loaiza Cano y Maira Beltrán (Eds.), Ensayos de historia cultural y política: Colombia, siglos XIX y XX, Cali, Universidad del Valle, 2012

Martínez Garnica, Armando, "La Independencia del Nuevo Reino de Granada. Estado de la representación histórica", Manuel Chust y José Antonio Serrano (Eds.), Debates sobre las independencias iberoamericanas, Madrid, Ahila, Iberoamericana, Vervuert, 2007.

Mejía, Sergio. La revolución en letras. La Historia de la Revolución de la República de Colombia de José Manuel Restrepo (1781-1863), Bogotá, Uniandes-Ceso, Universidad Eafit, 2007.

Melo, Jorge Orlando. "Historia. Colombia", en: Javier Fernández Sebastián (Dir.), Diccionario político y social del mundo iberoamericano. La era de las revoluciones, 1750-1850, Madrid, Fundación Carolina, 2009. 
Aproximación a ciertas nociones de historicidad en la prensa colombiana 417 durante la Independencia e inicios de la República en Colombia (1810-1827)

. "La literatura histórica en la República", Historiografía colombiana. Realidades y perspectivas, Medellín, Seduca, 1996.

Ocampo López, Javier. Historiografía y bibliografía de la emancipación del Nuevo Reino de Granada, Tunja, Universidad Pedagógica y Tecnológica de Colombia, 1969.

Ortega Martínez, Francisco A. y Alexander Chaparro, (Eds.) Disfraz y pluma de todos. Opinión pública y cultura política, siglos XVIII y XIX, Bogotá, Universidad Nacional de Colombia - University of Helsinki, 2012.

Pombo Manuel Antonio y José Joaquín Guerra. Constituciones de Colombia, Bogotá, Ministerio de Educación Nacional, 1951.

Real Academia Española, Diccionario de Autoridades, Madrid, Gredos, 1990.

Reyes Cárdenas, Catalina. "Balance y perspectivas de la historiografía sobre Independencia en Colombia", Historia y Espacio, No. 33, julio-diciembre 2009.

Rodríguez O., Jaime E. La independencia de la América española, México, Fondo de Cultura Económica, Colegio de México, Fideicomiso Historia de las Américas, 2005.

Silva Olarte, Renán. Prensa y revolución a finales del siglo XVIII, Medellín, La Carreta, 2004.

Vanegas Useche, Isidro. El constitucionalismo fundacional, 2a ed., Bogotá, Plural, 2014

\section{Prensa}

Argos de la Nueva Granada, Bogotá 1812-1816.

Aviso al público, Bogotá, 1810.

Boletín de Noticias del Día, Santafé, 1812.

Boletín de Providencias del Gobierno, Santafé, 1812-1813.

Boletín del Ejército del Sur, Popayán, 1814.

Correo de Bogotá, 1823.

Correo de la Ciudad de Bogotá, 1822-1823

Correo del Magdalena, Cartagena, 1825.

Década. Miscelánea de Cartagena, Cartagena, 1814.

El Bobo Entretenido, Bogotá, 1827.

El Censor, Bogotá, 1826.

El observador, Santafé, 1814.

La Bagatela, Santafé, 1811.

Suplemento a La Bagatela, Santafé, agosto de 1811. 
